\title{
Teaching Shakespeare in the Digital Age: The eZoomBook Approach
}

\author{
Christine Evain ${ }^{1} \&$ Chris De Marco ${ }^{2}$ \\ ${ }^{1}$ Ecole Centrale de Nantes, France \\ ${ }^{2}$ Audencia, France \\ Correspondence: Christine Evain, Ecole Centrale de Nantes, France. E-mail: christine.evain@ec-nantes.fr; \\ Chris De Marco, Audencia, France. E-mail: cdemarco@audencia.com
}

Received: March 15, 2016 Accepted: May 10, 2016 Online Published: May 11, 2016

doi: 10.5539/elt.v9n6p162 URL: http://dx.doi.org/10.5539/elt.v9n6p162

\begin{abstract}
What collaborative process can teachers offer in order to stimulate their students' reading of and writing on Shakespeare's plays? How can new technologies contribute to facilitating the classroom experience? The eZoomBook (eZB) template was designed for teachers to create and share multi-level digital books called "eZoomBooks" that allow readers to access enriched versions of the original, organized according to different tabs related to places mentioned in the original text. A zooming in and out function enables the readers of the eZoomBooks to navigate freely between the original and the enriched tabulated versions. This paper focuses on a pilot study of the methodology using a simplified version of the template. The targeted learners were English as a Second Language engineering students. Our objective is to show that the eZB framework and pedagogical applications are especially appropriate in making a difficult subject easier to teach (giving and correcting group assignments) and learn by providing learners an innovative and motivating approach to reading literature.
\end{abstract}

Keywords: eZoomBook, collaborative reading, digital template

\section{Introduction}

The eZB methodology and template make it possible to create multi-level documents called "eZoomBooks" where readers can access multiple and/or enriched versions of the original work. Organized in layers accessible by tabs in a menu, eZoombooks include a zooming in and out function allowing the readers to navigate between the original and the newly created enriched versions. The added-value of the template is that students themselves can collaboratively create an eZB by adapting and enriching the original version. The user-friendly eZB template makes it possible for teachers to guide students in this enriching of books not only to illustrate and promote a document in the public domain, but also to create an edited original book based on the teacher's and the class's own design.

The purpose of this paper is to show how the eZB methodology has been applied in the classroom to the teaching of Shakespeare in a French engineering school. This study aimed to test the methodology in terms of ease of use by instructors as well as student satisfaction and perception of the experience. After presenting the pedagogical context and relevant research, we will focus on two examples of how the template was used in a literature class on Shakespeare. In our first example, we will present the enrichment of one of Shakespeare's plays in the form of organized tabulations. Our second example, based on a teacher-developed course outline for a critical book, will allow us to demonstrate how the template can be applied to collaborative literary analysis. We will then discuss how the eZB template can help teachers set up a collaborative literature project to enhance possibilities for peer-to-peer learning within the classroom. In the conclusion, we will indicate the questions raised and the future developments for the eZB project.

\subsection{Gen $Z$ and Shakespeare}

Four-hundred years have passed since Shakespeare's death and pedagogues still agree that Shakespeare was "not of an age, but for all time". Throughout history, Shakespeare's plays have adapted to the times and Gen Z students are now confronted with the challenge of reading the plays as required subjects. Gen $Z$ is generally defined as the younger children of Generation X - in other words, Gen Z starts with today's teenagers. This generation has grown up with an array of communication tools that allow them to manipulate and enrich texts, select only what they want or need, and communicate in short, concise formulations. What could be more unlike 
Shakespeare than Twitter? However, Shakespeare can and should be reconciled with new technologies in that these tools can present his works in new and original ways.

Shakespeare was a deliberate choice for a pilot study since if the eZB methodology works for Shakespeare, it should work for other great works of literature often neglected for their apparent difficulty. Our experiment was carried out with French engineering students. These students were non-specialists not only in literature and the English language, but also never had exposure to the language of Shakespeare. The methodology thus had to take into account issues of linguistic competence, background cultural knowledge, and motivation to read outside of one's discipline and above one's level which demands an investment in time and effort. The methodology does not consist in "dumbing down" Shakespeare, but rather it aims to exploit technology for pedagogical purposes to make the reading of the original version more accessible to second language learners. The eZB methodology is a way to leverage the meaning of difficult and long texts by providing less-experienced readers with the tools to approach the original version in a step-wise, progressive fashion. EZoomBooks facilitate reading through a guided introduction of content (textual, visual, and aural). It is felt that this progression from a simpler, enriched version to the original version helps the reader better understand the original through the prior experience and knowledge gained from reading the simplified version. The zooming function makes it possible for the reader to increase or decrease the level of difficulty with an access to the complete original version, when needed.

The eZoomBook template is dual in scope in that students read as well as produce eZBs. The instructor can set in place a methodology to allow students to collectively work on adapting and enriching a portion of a difficult text. This collaborative work is an excellent means for groups of students to closely read a text and then produce coherent alternative versions for others to read. This helps students better understand the needs of the reader and the reading process as dependent on prior knowledge, cultural perspectives, and aspects of linguistic/discourse competence.

Using collaborative tools such as Google Drive, students can work on building the different types of tabs which will form the layers of the eZB. These layers can include multimedia elements such as sound effects and videos related to the material. Guided by teacher input, students prepare the chapter enrichments in the layers which are then compiled by the eZB template. A unique eZB is thus generated which can be distributed on any digital platform where readers outside the classroom can also have access to it.

\subsection{Pedagogical Context and Previous Research}

At the heart of the eZB methodology is the notion that the best way to show that you know something is to try to teach it to someone else. This idea is not new and it has inspired many practitioners from Andrew Bell's 1795 "mutual teaching method" to Jean-Pol Martin's (1985) 'learning by teaching' (Lernen durch Lehren, 'LdL') methodology, expanded on by Grzega and Schoner (2008). However, such a reversal of roles implies a conception of a classroom methodology that moves towards a more cooperative and collaborative model encompassing teacher-guided peer-to-peer interaction.

Publications on the subject of collaborative construction demonstrate the benefits of cooperation among students and analyze how these benefits can be enhanced. Hattie's meta-research (2009) provides a synthesis of these studies and highlights the main conclusions (Evain, De Marco, 2014, Evain, De Marco, \& Gutierrez, 2013, Evain, De Marco, \& Carolan, 2013). Trujillo (2002) classifies methods according to what they aim to promote: discovery learning, student team learning, learning together, and group investigation and concludes that "the differences between each method are the degree of structure in the task, the use of rewards, and individual assessment methods" (p. 8). Barkley, Cross, and Major (2005) focus on collaborative techniques which they classify in terms of problem solving, graphic organizers, writing, reciprocal teaching, and discussion techniques. Gross (2007) states that "each student's role can change along the process but it is essential to establish responsibilities to make sure students learn to work in groups" (p. 7). The key findings, here as applied to the eZB approach, are the need for the teacher to structure the task, the focused problem-solving nature of the student input, the responsibility that comes from assigned roles, and finally, the motivation in completing the production of an original group project that will be publicly displayed in a virtual format.

A research field has emerged that concentrates on the concept of personalizable virtual documents (PVD) and which seeks to measure their user effectiveness (Brusilovsky, Stock, \& Strapparava, 2000, Falquet, Nerima \& Ziswiler, 2004, Falquet \& Ziswiler, 2005). Hyperlinks and multimedia in their PVDs either provide additional information or record possible interpretation, or both. In the same way, the eZB approach allows for the personalization of documents, offering a multimedia customizable "elegant organization" approach. The added value of the eZB template is the zooming in and out functionalities to navigate between different levels of 
abridgements/enrichments and the full version of a document. In addition, like all PVDs, the eZB addresses the problems of teaching heterogenous groups by allowing leaners to use documents suited to their levels and needs.

To encourage a more active role during the learning process (Laurillard, 2002; Brewster, 2009; Lindberg \& Olofsson, 2010, Romainville \& Michaut, 2012), the eZB enrichments can also include interactive game strategies in the form of questions and quizzes, in line with the recommendations of Prensky (2001, 2012a, 2012b). While working on personalized eZBs, a group of learners will be collaboratively involved in producing a "library" of digital documents that are as easy to share and appreciate as the digital libraries highlighted in Heery and Lyon (2004) for the promotion of open knowledge and content (Iiyoshi \& Kumar, 2008).

Finally, the eZB approach follows a collaborative learning methodology described by Cassany (2008) and Johnson and Johnson (1997).

- The existence of positive group interdependence and a shared individual responsibility. The students' collaboration must result in an end-product and each participant adds a piece to the collective effort of building up an eZB.

- The formation of heterogeneous groups in terms of skills, competencies, and gender with expert readers helping non-expert or reluctant readers.

- The development of interpersonal communication skills and verbal and nonverbal communication skills through the presentation of the students' work and the assembling of the final eZB.

- The metacognitive group work during which students verbalize the processes underlying their understanding of the content and themes of the texts and receive feedback from their peers to which they have to respond.

Working collaboratively on an eZB project allows learners to 'negotiate' the meaning of the text in that each participant brings an interpretation to the table that must be analyzed and discussed among the group to arrive at a consensus on the meaning (our guidelines specifically stated that a consensus should be reached). The peer-to-peer inductive eZB methodology allows readers to take apart and then reconstruct a text to create these multiple but analogous versions. The pedagogy is thus process-oriented and requires learners to look closely at the parts in order to better understand the whole text.

\section{Method}

\subsection{Using the eZB Template}

At the heart of the eZB project is a blended-learning approach for the promotion of reading and collaborative writing through the development and structuring of "multi-scale" documents. The eZB template includes a range of functionalities enabling users to create enriched documents, select quotes from the original source, write up summary lines to connect the quotes, and produce multiple-scale documents in terms of level of abridgment.

The template makes use of existing tools to facilitate access to documents and the means for effective collaboration.

- An "elegant" Facebook-like organization for the forming of working groups (for example, our MOODLE systems which allows students to sign up for the projects we create),

- Collaborative work on the documents (for example, Google Doc),

- A user-friendly publishing and distribution system for the eZBs to be shared in a broader context, (our University Intranet),

- Connections to given databases (private and public resources) to stimulate the production of eZB, using the template (for example Gutenberg.org where Shakespeare's complete works can be found).

Our previous articles on eZB have shown the benefits of the eZB pedagogy to Gen Z readers who understand reading as an activity of sharing, deconstructing, and creating documents adapted to their needs - all of these activities being facilitated and enhanced by the electronic format. Enriched format and tailor-made documents are a given for this generation. The eZB template allows contributors to customize the length of documents. Readers of an eZB thus have a choice to read either the full version (always present on the platform) or modified shorter versions (enriched or not) that contributors create using the eZoomBook tool and methodology. Although our project involves a literary work with pedagogical applications, eZBs could be envisaged for a range of uses and needs - from lawyers who want multiple brief versions of a long case to students who want to review only the summaries of academic texts to researchers who may want to read the abridged versions of an article prior to the original. The objective is to use the template to create libraries of eZBs in different subjects which both 
enhance the reading experience and offer readers choices in how much they want or need to read.

The main pedagogical objectives of the eZB project are as follows.

- to offer a blended-learning system for the promotion of reading (in this context Shakespeare),

- to provide a forum for collaborative writing and synthesis of documents,

- to provide teachers with a methodology facilitated by the technology for organizing collaborative learning experiences,

- to develop curriculum materials for multiple uses (different targets, learning objectives, and contexts),

- $\quad$ to foster the means of 'learning by teaching' by giving students more control over the learning process and establishing a powerful connection among learning, reading, and the transmission of knowledge,

- to enhance student self-esteem and the learning process by making the classroom productions available to an outside audience.

While a group of researchers at the Ecole Centrale Nantes engineering school (ECN) in France is currently testing the adaptable eZB template available on our blog, the vocation of a future eZB platform is to be open to all readers and contributors and to include books and text resources in the public domain. As the platform is currently under development, we are using an open-source template for both examples of what we have produced in class (eZBs linked to the ECN Shakespeare class). Our eZB work template is available to all on our blog: https://ezoombookresearch.wordpress.com

\subsection{Example 1: Enriching Shakespeare's Plays}

To illustrate the potential uses of the eZB template and the related pedagogies, let us now turn to two examples, starting with the simplest one: enriching Shakespeare's plays - a project launched recently at the Ecole Centrale engineering school.

The twenty students participating in the experiment had signed up for an elective Shakespeare literature class as part of their English as a Foreign Language requirement. The students were undergraduates having studied English in secondary school for over 10 years. Their level was advanced in terms of everyday English, but they had never had to read works of literature extensively. As engineering students, they were highly skilled in using new technologies and were especially motivated to use these tools in their assignments. However, they were somewhat apprehensive about having to read plays and, in particular, Shakespeare's plays. The project aimed to demystify the reading task through a different presentation mode (electronic and not paper) and give readers more control over the level of difficulty (the zooming in and out function).

The material covered during the course was both Shakespeare's comedies and tragedies. After several teacher-led sessions on the background to Shakespeare's plays had taken place including several extracts of cinematographic adaptations, the eZB task was presented to students: to collaboratively create an enriched version of Romeo and Juliet. Possibilities for multimedia enrichments included links to different theatrical interpretations of scenes to be found on YouTube or multimedia sequences produced by the students themselves. At the end of the semester, the eZB was to be showcased on the University's intranet.

The following tabs on the eZB template were the architecture for building the eZB and students were assigned sections of the play and asked to summarize the material to be placed within the tabs and to search or create potential enrichments of the text:

1) Summary tab: selection of quotes and summary lines to link them.

2) Comprehension question tab: text-related questions (for example: "What happens when Romeo spots Juliet for the first time?").

3) Old English/Modern English tab.

4) Multimedia enrichment tabs (links to Shakespeare scenes on YouTube, teacher resource sites, such as: https://www.tes.com/teaching-shakespeare/?utm_campaign=GB-RES691, etc.)

\section{5) Critical commentaries tab}

Internet sources were pointed out to guide the students in selecting the content for the above tabs. Students were encouraged to explore, sample, and choose the resources that were meaningful to them. Here the information search process was part of the learning goals as students were guided to make effective use of the information sources available and collaboratively make judgments about the quality of what they found on the Internet. Having done that, the students could then write their introduction to their given scenes as well as their 
comprehension questions, commentaries and quizzes.

Since the eZB is not limited in layers, more tabs in addition to those indicated above could be created and these tabs would serve to highlight those textual elements in which the class is particularly interested. For example, student-produced enrichments can include audio material with read-out quotes, dialogues (both in modern or old English), re-enactment of Shakespeare's text, and student commentaries on their reaction to or interpretation of the play. Background context enrichment can be in the form of character maps or action diagrams, either as links or as material integrated into the eZB and produced by the students themselves. Such multimedia enrichments can help clarify the complexity of Shakespeare (dozens of characters in play, multiple plots and sub-plots) as well as highlight the poetic dimension of the text. For example, a historical fact tab would be useful when dealing with Shakespeare's historical plays to include comparisons between historical facts and Shakespeare's presentation or interpretation of these facts.

Perhaps most importantly, the textual quality of Shakespeare's writing can be singled out and highlighted through thematic tabulations where students select those parts of the text that have had the most impact on them. For example, the student may seek certain types of quotes (funny lines, famous lines, love lines, metaphors, etc.). Or they can create a "humorous lines" tab, or a "pearl of wisdom" tab which could be useful both for comedies and tragedies, since Shakespeare's is known to play with genre, including serious comments in comedies and comic lines in tragedies. All text selections can be connected to multimedia material such as readings or links to the LibriVox audiobook recordings.

In this blended learning format, teacher guidance is always available, but students are autonomous in choosing and illustrating their text enrichments. The creative element lies in transforming the work to better understand it and to make it better understood by other readers. This is where the learning by teaching approach is made concrete and visible in the end-product produced by the students (screenshots 1 to 6 in appendix A). When the student-produced enrichments are injected into the eZB template, a full eZB is produced allowing readers of the eZB to navigate freely between the different tabs.

\subsection{Example 2: An Original Collaborative Literary Analysis}

Our second example is only a slight variation from the first and it shows how even greater collaboration can be achieved between teachers and students. In this second example, the project consisted in enriching a critical book written by the teachers themselves. The book was entitled Shakespeare's plays: a thematic overview.

The critical book was made available to the students on the ECN Intranet. The students were told to choose one chapter they wanted to enrich. The structure of the book was very simple and easy for the students to understand, and for each chapter the students were given the reference of a scene illustrating the chapter in question. The work that the students needed to do in relation to the scene was exactly the same as the one previously described and which concerned Shakespeare's play Romeo and Juliet. The five tabs regarding the enrichments were identical.

However, the resulting eZB was different because in this second assignment the objective was to enrich a critical book and not a play. This critical book mirrored the course the students were attending: it was a thematic overview of Shakespeare's plays focused on two main themes:

- True or false allies in Shakespeare's plays. This was articulated in four parts showing how true or false allies brought about happy or disastrous consequences - all four combinations were illustrated by scenes from comedies and tragedies.

- $\quad$ Power politics between sexes: a full range of possibilities emerged including the following examples.

- Equality between sexes,

- Wives obeying their husbands,

- Maiden sacrificed and then saved,

- Women inverting power games in their favor,

- Women dominating their husbands or lover

- Silly power games.

The students chose a scene from the list the teachers had provided to them. They then enriched the scenes in question on a Google Drive document. This document allowed all students to see which scenes had already been picked, to follow their peer's progress, to exchange suggestions and comments, and to read the teacher's corrections for all the work produced by the class. Once the content of the different layers was finalized, it was 
injected into the eZB template to produce an eZB which was then posted on the teacher's research blog.

\subsection{Teacher/Student Dynamics}

The two examples of eZB constructions provided here show the class dynamics, the teacher's role, and the outcome of the project. However, the approach is extremely flexible since both the structure of eZBs and the project guidelines can be adapted to various teaching contexts, content, and objectives. Furthermore, the tabulation articulation is either included in the teacher's guidelines or left for the contributor to create, according to his/her reading and interpretation of the text. In the case of our experiment, the five-tabulation articulation can serve as a guideline to ask student-contributors to explore every single one of Shakespeare's plays. It could be easily adapted for the enrichment of other great works of literature in the public domain or for other critical books.

Indeed, when using the eZB template, teachers may choose to set specific guidelines which go so far as to provide a definite structure to the tabs and layers of the contributor-created eZoomBook, as in our own examples. Alternatively, pedagogues may choose to keep the guidelines open, or they may simply provide a significant example on their Intranet or blog which then allows students to shape their own work according to their own objectives. This open guideline logic and possibility for contributors/students to direct their own work is in keeping with the notion of Concept-Oriented Reading Instruction (CORI) (Guthrie, 2007, 2009), or Personalized System of Instruction (PSI) (Keller, 1969, 1982), (Keller \& Sherman, 1974), which has been widely commented on in Hattie's work, mainly in respect to student motivation (Hattie, 2009).

Although the two examples above tend to emphasize teacher/student collaboration (with more or less explicit guidelines depending on the teacher's pedagogical choices), the template has been devised with a larger contributor target in mind. Our template aims with future development at becoming a free-contributing system like Wikipedia - allowing for anyone to enhance and have access to the resources on the platform. It must be noted, however, that for lifelong learners to benefit fully from such an experience, a collaboration or tutoring system can provide a complement to resources that alone may be insufficent.

\section{Results}

\subsection{Student Results}

Samples of eZBs produced in class as well as the guidelines of the methodology are available on our blog (https://ezoombookresearch.wordpress.com/what-is-ezb-ezoombook-examples/). Student satisfaction was measured through the standard ECN student questionnaire which assesses four main variables of the classroom context: course content; workload appropriateness; evaluation system; quality of teaching. The students' level of satisfaction was measured on a Likert scale from 1 (not at all satisfied) to 5 (extremely satisfied). Using the standard questionnaire made it possible to compare the 2016 Shakespeare class with that of 2015 . The teaching conditions were the same for these two classes (same content, same teachers, same feedback mechanism); the only difference was that it was only in 2016 that the eZB methodology was used as a class project and as an evaluation system.

Although the group size was small (20), the results are worth analysing because of the visible difference between the results of the 2016 Shakespeare class and the 2015 group. The feedback questionnaire response rate was higher in 2016 but perhaps not significantly so (60\% against 50\%). This can be interpreted as a stronger desire to give feedback and this feedback was indeed more positive in 2016 than in 2015. The two tables below summarize the results of the questionnaires per group.

2016 eZB group responses

\begin{tabular}{|l|l|l|l|l|l|}
\hline & 1 & 2 & 3 & 4 & 5 \\
\hline Course content & & & & $58 \%$ & $42 \%$ \\
\hline Workload appriateness & $8.3 \%$ & $8.3 \%$ & $25 \%$ & $42 \%$ & $16.7 \%$ \\
\hline Evaluation system & & $8.3 \%$ & $25 \%$ & $58 \%$ & $8.3 \%$ \\
\hline Quality of teaching & & & & $16,7 \%$ & $83.3 \%$ \\
\hline Total (overall satisfaction): & $2.1 \%$ & $4.2 \%$ & $12.5 \%$ & $43.7 \%$ & $37 \%$ \\
\hline
\end{tabular}


2015 group responses

\begin{tabular}{|l|l|l|l|l|l|}
\hline & 1 & 2 & 3 & 4 & 5 \\
\hline Course content & & & $10 \%$ & $30 \%$ & $60 \%$ \\
\hline Workload appropriateness & $10 \%$ & $30 \%$ & $60 \%$ & & \\
\hline Evaluation system & $10 \%$ & $10 \%$ & $30 \%$ & $50 \%$ & \\
\hline Quality of teaching & & & $10 \%$ & $30 \%$ & $60 \%$ \\
\hline Total (overall satisfaction): & $5 \%$ & $10 \%$ & $27.5 \%$ & $27.5 \%$ & $30 \%$ \\
\hline
\end{tabular}

1 (not at all satisfied); 5 (extremely satisfied).

The eZB group expressed a very high level of satisfaction: $43.7 \%$ "very satisfied" and 37\% "extremely satisfied". The two main areas of improvement were "Workload" and the "Evaluation system" but the other two areas were also impacted, mainly the "quality of teaching" which was better perceived because of eZB. Although this may be a "halo" effect, it is interesting to note the highly positive comments in the feedback given in the open "additional comments" section. Some of the reccuring comments of the eZB group were that the course had given them a complete overview of Shakespeare's plays, that the blended learning format of the course had been appreciated, and that the eZB homework was "meaningful", useful", "easy to understand" and "interesting group work". The tool used for their eZB homework (both the eZB template and Google Drive) was said to be "easy to use".

The student coordinator, in charge of using the eZB template for the "Shakespeare's plays: a thematic overview" book said that the Google Drive document proved to be effective for students to include their enrichments and share their work. The student coordinator found it simple to use and to produce a full eZB which included all the chapters produced by the class. The main criticism concerned the hyperlink system between the different eZB layers: these hyperlinks have to be created one by one, using the Sigil editing system, and this was found to be tedious.

Student suggestions included their desire to cover more plays, extend the course duration, and measure how effectively they succeeded in passing on their knowledge to others. For this, in the future, metrics could be included in the ECN intranet system to measure the number of downloads or readings achieved by the student-produced eZB.

\subsection{Feedback from Teachers}

Teachers participating in the experiment found that the students had produced high-quality work and systematically met their given deadlines. The work related to eZB construction was achieved in total autonomy which led to peer-to-peer collaboration within the class, as the project was not perceived as a top-down, teacher driven activity. This peer-to-peer collaboration was visible in the way the students spontaneously organized their work within their groups of four students. All groups created a shared document system (using Dropbox or Google Drive) to allow for easy peer-to-peer corrections. The class motivation was greatly appreciated by the teachers. Furthermore, subsequent to the student corrections of assignments, the amount of correction for the teachers was greatly reduced. Given that both the guidelines and the tool can be re-used on different material, new classes can be set up with minimum work spent on redesigning the syllabus.

When analysing the student questionnaire, the teachers were both pleased and puzzled to see that their "quality of teaching" had been rated higher in 2016. This may be attributed to several distinguishing features of the eZB methodology:

- more course time dedicated Shakespeare's work (and less to guidelines concerning the grading system and the end-of-term individual assignment);

- more student energy focused on the course and the projects rather than an end-of-term individual graded assignment;

- teachers were also motivated by showcasing the work of their class in the form of eZBs to future groups of students.

The teacher motivation is therefore similar to the students' own motivation in that both take pride in creating a lasting product which serves the purpose of promoting the work accomplished in class. 


\section{Discussion and Conclusion}

The two examples we have chosen in this article illustrate possible pedagogical applications of the eZB template. Both examples are based on Shakespeare. However, the choice of source material for the construction of eZBs is open and the scope is vast: every long text or document (novel, short story, play, critical book, essay, textbook, research article, etc.) offers possibilities of constructing multi-layered enriched texts. Pedagogues and contributors can therefore choose books according to their objectives and adapt the eZB pedagogy to give students the means to co-produce a multi-layered book or document. In addition, the definition of the types of tabs or "layers" within the eZB framework is open and can be extended to other pedagogical aims depending on the targeted learner's needs. While the eZBs of our two examples were created in relation to reading assignments, they can also be created as an extra step to collaborative writing, whether essay writing, creative writing, rewriting, or even translation. All these different aspects can be enriched through the multi-layer system of abridged version and enriched versions defined by tabs.

Furthermore, there are many conceptual approaches that pedagogues developing eZB projects can build on. These approaches promote collaborative work and are therefore linked to strategic tool choices which are made depending on what the teaching environments have to offer. Some learning institutions have pedagogical platforms that are convenient to use (Moodle, Blackboard, etc.). Other collaborative tools can be found on the Internet (Google Drive, Dropbox, etc.). The strategies of collaborative projects are now becoming better-known and they promote teacher-student collaboration, prior to the use of the template, which is most important.

Equally important is the way the eZB are shared once they have been produced. eZB projects give students a chance to explore subjects related to self-publishing and the promotion of books. They can be involved in many more tasks in relation to the eZB they construct: creating the group's authoring profile, comparing and using self-publishing platforms, creating content in order to promote the book on social media, etc. While tools similar to the eZB concept exists (hyperlinking on wikis), we feel that the eZB methodlogy is unique in several ways: its combination of traditional and digital components, the flexibility of adding tabs corresponding to the needs of the reader, the tailor-made nature of the layers, the possibilities for specific enrichments, the open-source nature of the software, the adaptability of the methodology to a variety of written sources and audiences.

\subsection{Further Studies}

This was a pilot project and therefore future experiments will include more quantitative measures on the effectiveness of the eZB methodology to motivate students to work through and better understand long and difficult course material. Our goal will be to provide the answers to questions such as the following:

- How does the enrichment task change the perception of the resource?

- How does the eZB construction facilitate the understanding and assimilation of the resource by the learner? How does it enhance motivation and consequently learning?

- An eZB, which combines an original source (the book) and additional layers, is "more" than a book: how is it perceived by the reader? How does reading an eZB layer affect the comprehension of the original version?

- What is the right blend between traditional and innovative methods? Learning methods in reading are adaping to the new technologies and this can be seen as both a challenge and a threat. What is the best way to conciliate the new and the old?

- What are the possible impacts on e-reading devices and what approach can we recommend to teachers and students?

Carrying out further studies would imply developing the eZB template so that it would become even more user friendly. Among the extra functionalities which are being added is one for combining chapters, allowing students to produce their chapters independently for future assembly. For the moment, when using the eZB methodology, teachers need to appoint a group coordinator in charge of injecting all the student material into the eZB template.

The results of this pilot project are encouraging and show that the methodology is easy to use in the classroom and leads to student satisfaction even when the course content is especially challenging and difficult. Most importantly, those teachers in the pilot project felt that their role was enhanced through the collaborative and co-operative work atmosphere that is an intrinsic part of the methodology. More research is needed to see how the methodology can apply to varying groups of learners (first and second language; reluctant and experienced readers; children and adults, etc.) and how the methodology affects reading comprehension.

The eZB approach to reading offers an alternative to reading the original version, with the option of zooming up to the original always present. Students can be both readers and writers of eZBs and the template facilitates 
student-teacher interaction in the classroom. Having such choices underlies the added-value of the methodology.

\section{Acknowledgements}

We would like to thank the ENJEUX programme for their financial help in the development of the eZB template.

\section{References}

Barkley, E. F., Cross, K. P., \& Major, C. H. (2005). Collaborative learning techniques: A handbook for college faculty. San Francisco, CA: Jossey-Bass.

Bell, A. (1816). Instructions for conducting schools through the agency of the scholars themselves. Oxford University Archives. London.

Brewster, D. (2009). Interrupted Conversations: Enhancing Laurillard's conversational framework to take account of disruption (Unpublished doctoral dissertation). University of Sussex, Brighton, UK.

Brusilovsky, P., Stock, O., \& Strapparava, C. (Ed.). (2000). Adaptive hypermedia and adaptive Web-based systems: international conference, AH 2000, Trento, Italy, August 28-30, 2000: proceedings. Berlin; New York: Springer.

Cassany, D. (2008). Prácticas letradas contemporaneas. México: Rios de Tinta.

Davidson, C. N. (2011). Now you see it: how the brain science of attention will transform the way we live, work, and learn. New York: Viking.

De Marco, C. Evain, C., \& Gutierrez, F. (2013). Enhancing the Reading Experience through User-Generated Serious Games on the MyGame-4u Platform. In M. Ma, M. F. Oliveira, S. Petersen, \& J. B. Hauge (Ed.), Serious Games Development and Applications (pp. 96-107). Springer Berlin Heidelberg. http://dx.doi.org/10.1007/978-3-642-40790-1_10

ECDL (Conference), Heery, R., \& Lyon, E. (Ed.). (2004). Research and advanced technology for digital libraries: 8th European conference, ECDL 2004, Bath, UK, September 12-17, 2004 : proceedings. Berlin; New York: Springer.

Evain, C., \& De Marco, C. (2014). Reading with a Difference: eZoomBook and MyGame-4. Publishing Research Quarterly, 30 (1), 50-62. http://doi.org/10.1007/s12109-014-9352-9

Evain C, \& De Marco C. (2014). Reinventing the book: The eZoomBook platform. Ubiquitous Learning, 7(1), $1-13$.

Evain, C., De Marco, C., \& Carolan, S. (2013). Le nouveau dispositif 'eZoomBook' : Perspectives pédagogiques. Distances et médiations des savoirs. Distance and Mediation of Knowledge, 1(3). http://dx.doi.org/10.4000/dms.337

Falquet, G., \& Ziswiler, J.-C. (2005). A Virtual hyperbooks model to support collaborative learning. International Journal on E-Learning, 4(1).

Falquet, Nerima, L., \& Ziswiler, J.-C. (2004). Towards digital libraries of virtual hyperbooks. USA. http://dx.doi.org/10.1145/1012807.1012815

Grzega, J., \& Schoner, M. (2008). The didactic model LdL (Lernen durch Lehren) as a way of preparing students for communication in a knowledge society. Journal of Education for Teaching, 34(3), 167-175. http://dx.doi.org/10.1080/02607470802212157

Guthrie, J. T., McRae, A., Coddington, C. S., Lutz, K. S., Wigfield, A., \& Barbosa, P. (2009). Impacts of comprehensive reading instruction on diverse outcomes of low- and high-achieving readers. Journal of Learning Disabilities, 42(3), 195-214. http://dx.doi.org/10.1177/0022219408331039

Guthrie, J. T., McRae, A., \& Klauda, S. L. (2007). Contributions of Concept-Oriented Reading Instruction to Knowledge about Interventions for Motivations in Reading. Educational Psychologist, 42(4), 237-250. http://dx.doi.org/10.1080/00461520701621087

Gross, B. (2007). El aprendizaje colaborativo a través de la Red: límites y posibilidades [Collaborative learning through the Internet: Possibilities and boundaries]. Revista Aula de innovación educativa, 162, 44-50.

Hattie, J. (2009). Visible learning: a synthesis of over 800 meta-analyses relating to achievement. London; New York: Routledge.

Hattie, J. (2012). Visible learning for teachers: maximizing impact on learning. London; New York: Routledge. 
Hattie, J., \& Anderman, E. M. (2012). International guide to student achievement. New York, NY: Routledge.

Hattie, J., \& Yates, G. C. R. (2014). Visible learning and the science of how we learn. New York, NY: Routledge.

Iiyoshi, T., Kumar, M. S. V., \& Carnegie Foundation for the Advancement of Teaching. (2008). Opening up education: the collective advancement of education through open technology, open content, and open knowledge. Cambridge, Mass.: MIT Press.

Jarvis, J. (2009). What would Google do? New York, NY: Collins Business.

Jenkins, H. (2009). Confronting the challenges of participatory culture: Media education for the 21st century. Cambridge, US: The MIT Press.

Johnson, D., W., \& Johnson, F., P. (2012). Joining together. Group theory ... New York, N.Y: Pearson Education.

Keller, F. S. (1969). A programmed system of instruction. Kalamazoo, Mich.: Western Michigan University.

Keller, F. S. (1982). Pedagogue's progress. Lawrence, Kan.: TRI Publications.

Keller, F. S., \& Sherman, J. G. (1974). PSI, the Keller plan handbook: essays on a personalized system of instruction. Menlo Park, Calif.: W.A. Benjamin.

Kivunja, C. (2013). Theoretical Perspectives of How Digital Natives Learn. IJHE International Journal of Higher Education, 3(1), 94-109.

Laurillard, D. (2002). Rethinking university teaching a conversational framework for the effective use of learning technologies. London; New York: Routledge/Falmer. Consulté à l'adresse http://dx.doi.org/10.4324/9780203304846

Lindberg, J. O., \& Olofsson, A. D. (2010). Online learning communities and teacher professional development methods for improved education delivery. Hershey, PA: Information Science Reference. Consulté à l'adresse http://search.ebscohost.com/login.aspx?direct=true\&scope=site\&db=nlebk\&db=nlabk\&AN=272470

Martin, J.-P. (1985). Zum Aufbau didaktischer Teilkompetenzen beim Schüler: Fremdsprachenunterricht auf der lerntheoretischen Basis des Informationsverarbeitungsansatzes. Tübingen: Narr.

Palfrey, J. G., \& Gasser, U. (2008). Born digital: understanding the first generation of digital natives. New York: Basic Books.

Prensky, M. (2001). Digital game-based learning. New York: McGraw-Hill. http://www.ebrary.com/

Prensky, M. (2012a). Brain gain: technology and the quest for digital wisdom. New York, NY: Palgrave Macmillan.

Prensky, M. (2012b). From digital natives to digital wisdom: hopeful essays for 21 st century learning. Thousand Oaks, Calif.: Corwin. http://dx.doi.org/10.4135/9781483387765

Romainville, M., \& Michaut, C. (2012). Réussite, échec et abandon dans l'enseignement supérieur. Bruxelles: De Boeck.

Trujillo Sáez, F. (2002). Aprendizaje cooperativo para laenseñanza de la lengua. http://digibug.ugr.es/handle/10481/23943

Trujillo Sáez, F. (2015). 'La verdad es que yo he nacido esta mañana': notas sobre el PLC para una visita al IES Chaves Nogales. http://fernandotrujillo.es/plc-en-el-ies-chaves-nogales/ 


\section{Appendix A}

\section{Screenshots below of eZB layers}

The screenshots below show the different layers of an eZB. Readers of the eZB can navigate freely between the different tabs which showcase the students' enrichments. For example, Figures 1 and 2 give parallel versions of Shakespeare's text: one in Shakespeare's original English and one in modern English. Figures 3, 4, 5, 6 are student enrichments, explained below. Figure 7 shows the table of content of the second eZB enrichment project.

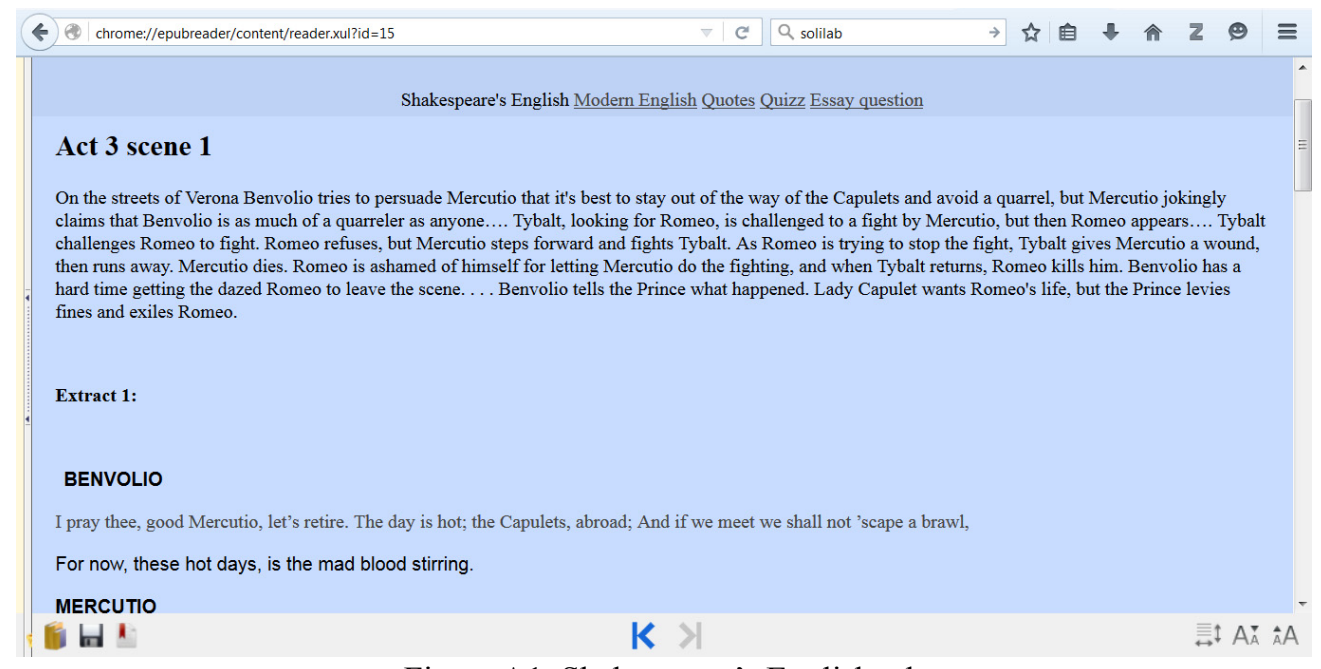

Figure A1. Shakespeare's English tab

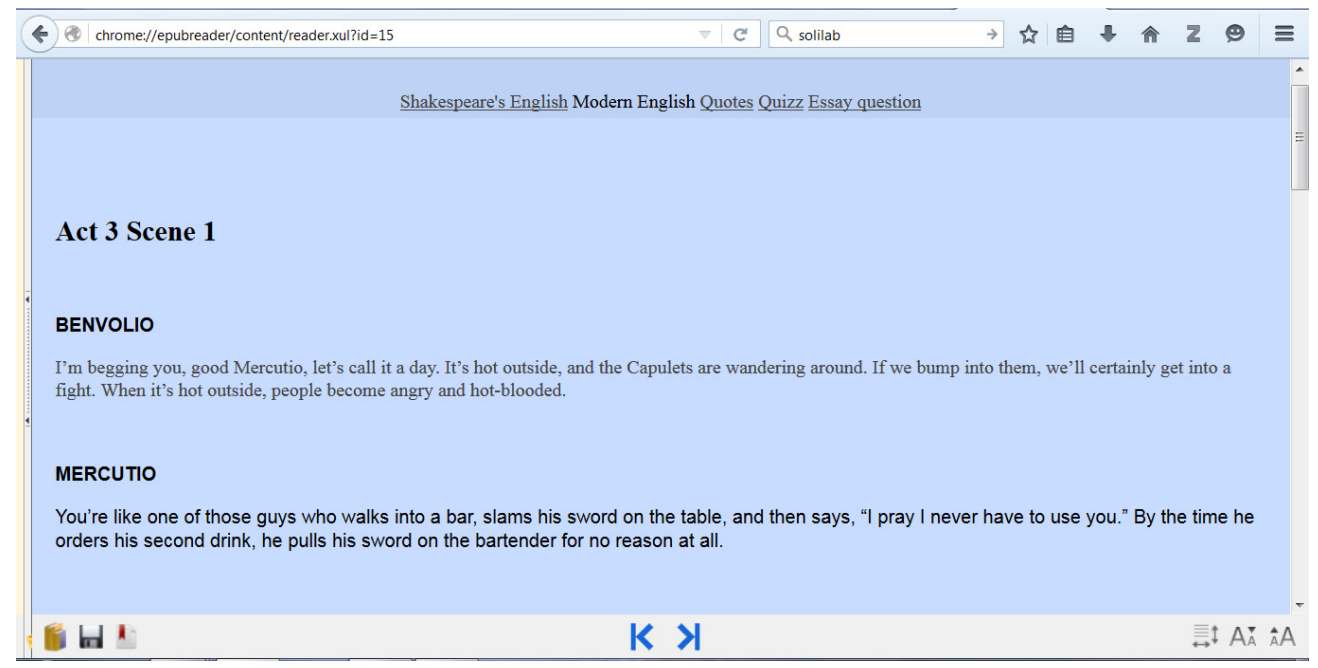

Figure A2. Modern English tab 


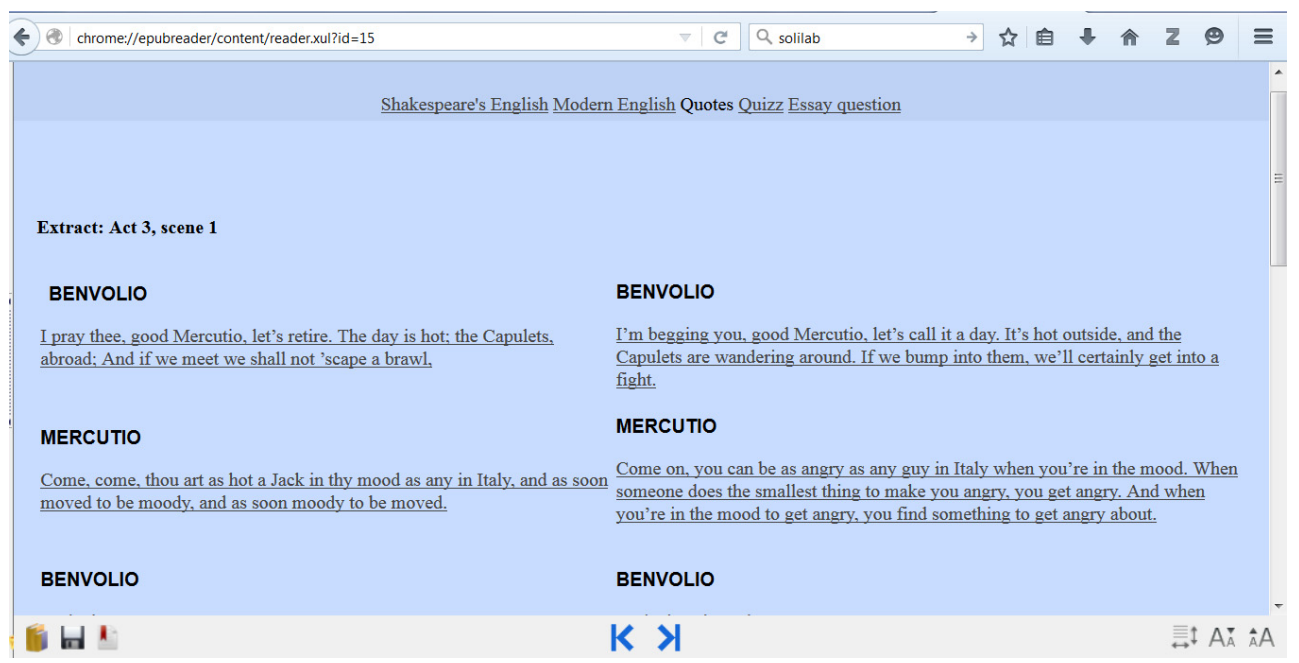

Figure A3. Quotes tab

When a reader clicks on a given quote in this abridged version of the text, he lands on the same quote in the unabridged version of the text, whether the quote is in Shakespeare's English or in modern English.

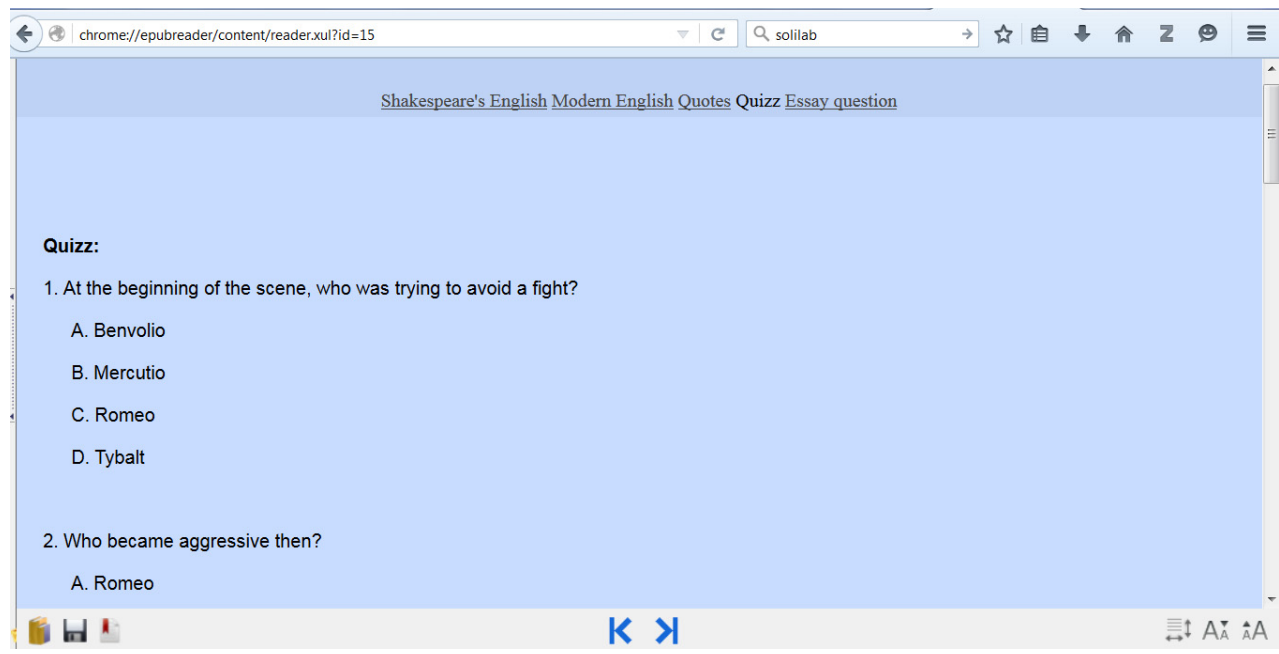

Figure A4. Quizz tab 


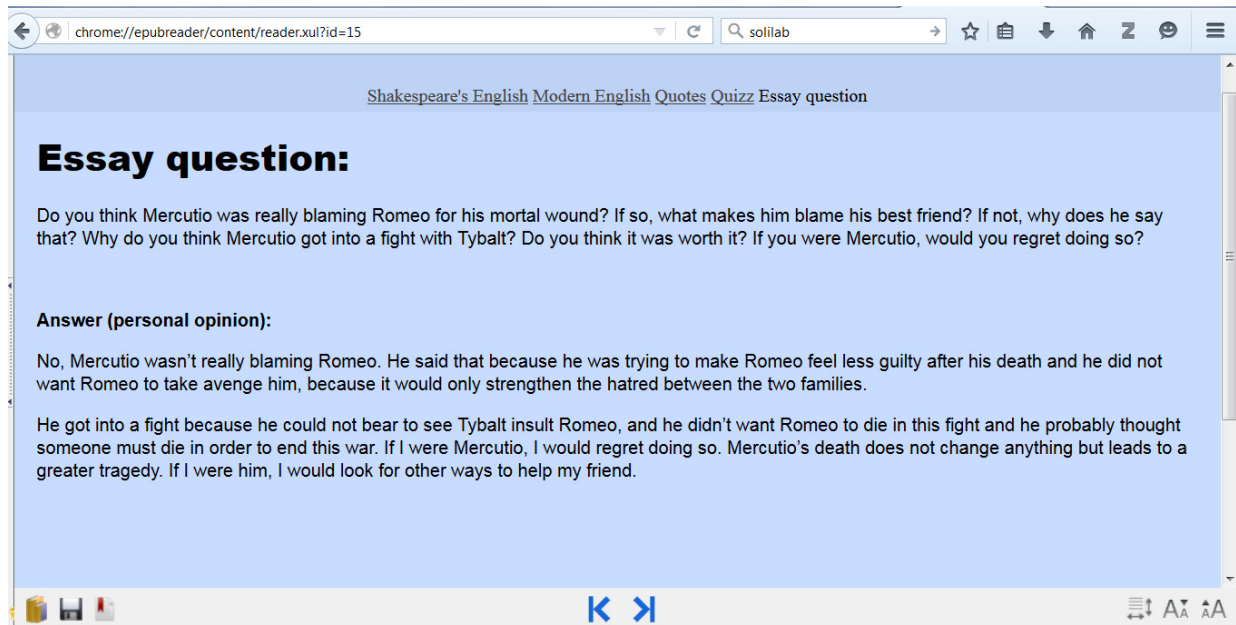

Figure A5. Essay question tab

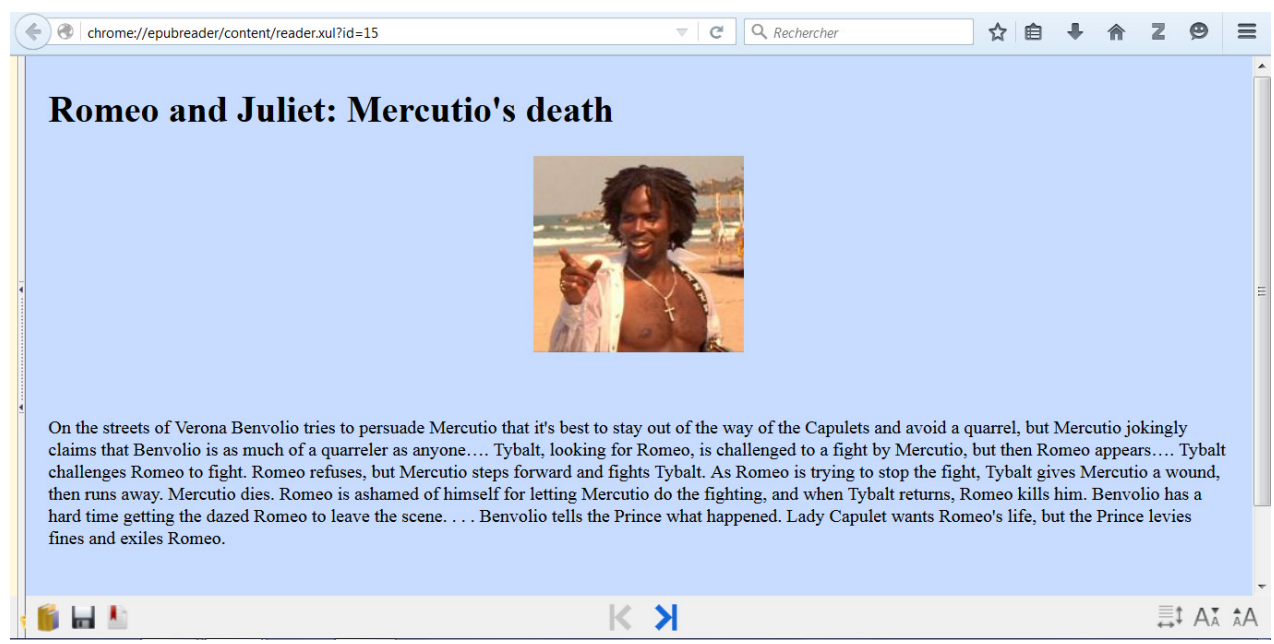

Figure A6. Visual enrichments

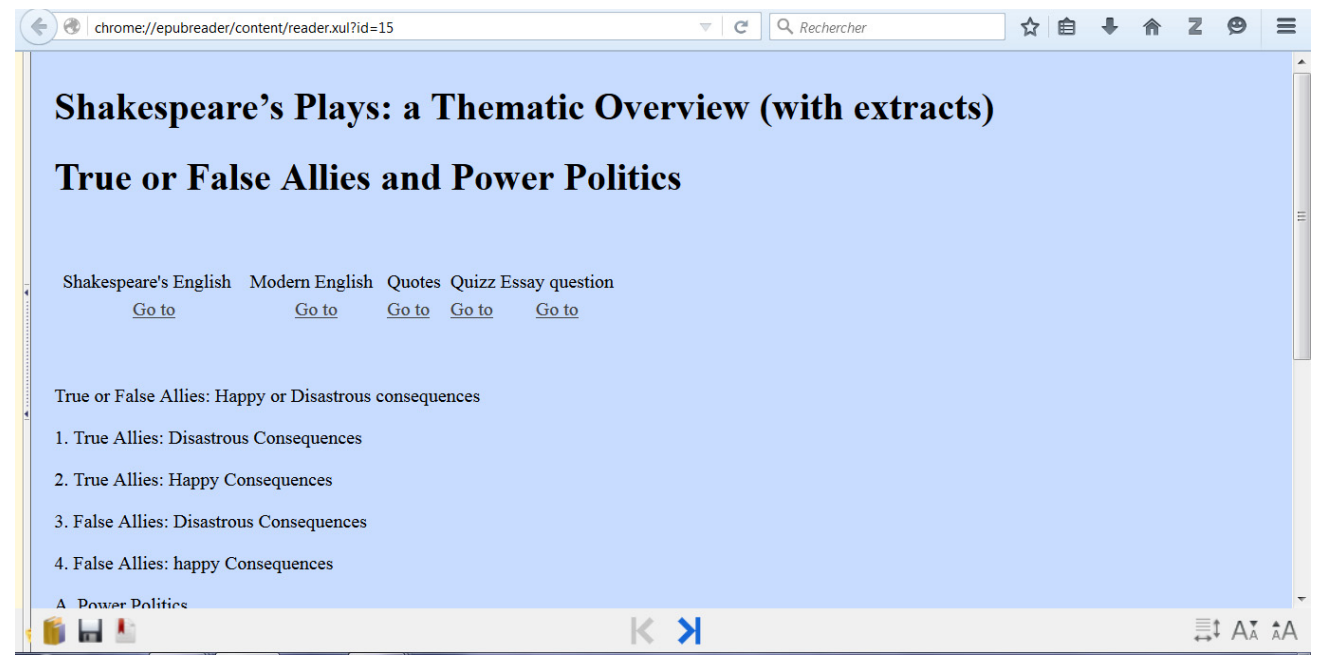

Figure A7. 2nd eZoomBook Project: enrichment of course book 


\section{Copyrights}

Copyright for this article is retained by the author(s), with first publication rights granted to the journal.

This is an open-access article distributed under the terms and conditions of the Creative Commons Attribution license (http://creativecommons.org/licenses/by/3.0/). 